tonsils three times. In none of these fourteen children were there any changes of note in the larynx.

The treatment was divided as follows: removal of adenoid vegetations and of tonsils in six cases; cauterization of the turbinated bodies and the employment of bougies in eight ; inflation in fourteen.

As regards operations, the writer dwells upon the difficulties which he met with at first in obtaining the consent of parents for the six operations, which were the first which had been practised in the institution since its foundation in the year 1852 .

Before giving the results of the treatment the writer refers to their object. There are three indications : first, to remove all obstruction to nasal respiration; second, to remove any condition interfering with the articulation of words; third, to endeavour to improve audition in every possible way.

This classification points specially to the oral method universally employed in the instruction of deaf mutes at the present day. For learning to speak, the deaf mute ought to respire normally. It is more necessary for him than for the normal child that there should be nothing interfering with articulation. These two primary principles are not sufficiently recognized by the teachers in the institutions, because no one has enlightened them upon this point.

Lastly, any improvement in the hearing, even in the slightest degree, is of the greatest service to the deaf mute. Those who hear, even though only words uttered close to the ear, acquire more easily and more thoroughly the oral method than the others. A radical cure is not the only object of the medical attendant, and he ought not to neglect any case where the slightest improvement in audition may be obtainable.

The results obtained in six months by the author have been-(I) As regards respiration: six cases, six cures. (2) As regards speech : speech distinct, two cases; speech improved, four cases. (3) Hearing power: fourteen cases, thirteen improvements.

There is no difficulty in drawing an inference from these encouraging results, and it is much to be desired that all institutions should have a medical specialist, devoting his time entirely to the pupils and the instruction of the young deaf mutes, who have been absolutely neglected up to the present.

D. G.

\title{
THE PRELIMINARY TRAINING AND METHODS OF OPERATING ON LARYNGEAL GROWTHS per vias naturales.
}

\author{
By J. Middlemass Hunt, M.B., ${ }^{x}$ \\ Laryngologist, Royal Infirmary, Liverpool.
}

I' was with much pleasure that I accepted the invitation of our President to open a discussion on "The preliminary training and methods of operating

1 Read at the July meeting of the British Laryngological, Rhinological, and Otological A ociation. 
on laryngeal growths per zias naturales." First, because the subject is one in which I have taken some interest, and secondly, because it has not, so far as I know, been up for discussion before any Society of Laryngologists within recent years. The rapid advances which laryngology has been making in other directions have tended to throw this subject into the background, and it is time to look round and inquire if the great increase in the number of workers in our specialty has led to any improvements in our methods of intralaryngeal operation for benign growth. As you are all aware, it was in this department that the early laryngologists won their greatest triumphs, and it was the skill required for these delicate manipulations which largely justified the separation of laryngology from general surgery. We are reminded of this when we recall the names of Von Bruns, Stoerk, Fauvel, Schroetter, and Mackenzie, all known to us as dexterous intralaryngeal operators. I sometimes doubt whether the laryngologists of the present generation are equal in manipulative dexterity to the men of the pre-cocaine era, as we may call it. In their time no one ventured to introduce a laryngeal forceps till his hand and eye had become thoroughly trained by long-continued practice ; in ours, the six weeks' student of some post-graduate course thinks himself equal to any intralaryngeal operation. Now, that the introduction of cocaine anrsthesia has greatly shortened the preliminary training required by the patient, and has immensely simplified all intralaryngeal operations, must be admitted; but that it has removed all difficulties, and has made it possible for the unskilled to operate with impunity is certainly far from correct. There are still cases which tax the resource and patience of the operator and the endurance of the patient; cases in which some anatomical peculiarity of the tongue or epiglottis, something in the situation and character of the growth, the age of the patient, or an excessive irritability, only partially, or not at all, controlled by cocaine, renders intralaryngeal operation exceedingly difficult to accomplish. I think we sometimes over-estimate what cocaine has done for us. While it is true that in pre-cocaine times some cases required a prolonged training before operation, such was by no means the rule. In the great majority the patient was ready for operation in from three to eight days, if training was carried out systematically; and the dexternus operator could, even in those times, often remove growths without any preliminary training at all. Then, as now, the tolerance and intelligence of the patient, the courage and dexterity of the operator, and the site, size, and nature of the growth were the factors which determined the length of time necessary to complete an intralaryngeal operation.

Has cocaine done away with the need for any preliminary training? We do meet with cases in which a growth can be removed at a first visit, but I confess I have seldom tried, considering it better to educate the patient for a few days in the passage of instruments, and so make certain, if possible, of seizing the growth at the first attempt. As I mostly employ tube forceps for these operations, the forceps can be used as a laryngeal probe, and we thus gain a knowledge of any change in curvature, or in the setting of the blades, required for the case in hand. Cocaine does not allay fear or remove awkwardness on the part of the 
patient, but a few days' training will. Of course, we must also be guided by the urgency of the symptoms and the time at the disposal of the patient.

There are two objections to cocaine anæsthesia of the larynx, which in my experience apply in rare cases only. In certain nervous subjects its effect is exactly contrary to that intended, and the patient becomes so irritable that no operation can be carried out. This has only happened once to me, in the case of a boy with laryngeal papillomata, on whom tracheotomy had been performed. Cocaine, though applied frequently and in strong solutions, only made things worse, and I had to remove the growths in numerous sittings without any anæsthesia. With some perseverance, however, the case did well. The tracheotomy tube, which had been worn for over a year, was removed, and there has been no recurrence in the five years which have since elapsed.

A second objection to cocaine as an anæsthetic in laryngeal operations is its uncertainty, and the short duration of the anæsthesia in many cases. I think the uncertainty is more due to the method of application, and the strength of the solution employed, than to any other cause. In applying cocaine to the larynx our object is to reach every part of the mucous membrane with the smallest amount of irritation and the least expenditure of the drug. To accomplish this three methods are in use : (I) swabbing by means of a brush or cotton wool mop ; (2) the use of a fine spray; and (3) the introduction of the solution in drops by means of a syringe. No doubt all these methods bring about the same result, though probably the spray is the most perfect. I have never employed it, however, for this purpose, through fear of poisoning from the application of twenty per cent. solutions (as recommended by Bosworth), and have confined myself to the use of the cotton wool mop. Where this method fails, it is usually due to the use of solutions which are too weak or are not applied with sufficient care and thoroughness. As cocaine only acts on the parts it is brought into direct contact with, every part of the larynx must be reached with the brush. The pharynx, I think, is better left alone, unless it is very irritable, when the best application can be made by means of a spray of not more than five per cent. If cocaine be used in this way failure to procure anæsthesia will be rare, and symptoms of poisoning will hardly ever occur. While I have frequently seen poisoning follow its use in the nasal cavities, I have only seen it in one patient after an intralaryngeal application. In this case there was evidently a marked idiosyncrasy, as the patient had severe symptoms of cocaine poisoning on three separate occasions when a twenty per cent. solution had been applied before the removal of laryngeal warts.

As regards the strength of solution, I think that less than twenty per cent. will seldom suffice to produce complete anæsthesia, either in children or adults.

The duration of cocaine anæsthesia in the larynx is unfortunately comparatively short, lasting from three to seven minutes as a rule-rarely longer. Of course another application can be made, but one finds that if reflex irritability has returned, we seldom get such complete anæsthesia again at the same sitting. I do not employ any accurate method of 
measuring the dose of cocaine, but my rule is that if three to six brushings with a twenty per cent. solution are not sufficient, it is better to postpone operation.

It is curious how the effect of cocaine will vary, even in the same patient, on different days. On one day we will get complete anzesthesiat with two or three applications, and on another twice that number will fail.

Having trained our patient and got complete anaesthesia, how shall we operate? What instruments shall we employ? That will depend primarily on the preferences of the individual operator, and also on the size, character, and situation of the growth to be removed. Practically there are three methods of removing laryngeal growths. They may be torn off, or cut off, or scraped off. Technically these methods are named evulsion, abscission, and curcttage (curetting).

For the evulsion of growths, forceps of various shapes and sizes are employed, the blades of which are slightly hollowed and have their edges serrated, so as to take a good hold. This method may be used for most growths, but is best suited for soft and more or less pedunculated growths. The objection to it is that, if the growth be firmly attached, we may remove along with it more or less of the mucous membrane; or even, if much force be used, may tear a vocal cord from its attachment. This once happened to Voltolini with the unfortunate result of involving him in an action at law. The amount of force used in this method must therefore be carefully regulated, and if the growth does not come away easily, it should be let go and some form of cutting instrument employed.

For the abscission of growths various instruments such as cutting forceps, knives, snares, and guillotines are employed. The laryngeal snare is an instrument which in pre-cocaine days found especial favour in this country at least. It is not an instrument of precision, and the man who relies upon it alone will not get very far as a laryngeal operator. Its chief merit is that one can scarcely do any harm with it. In two conditions only have I found it of use: in cases of multiple papillomata, where the larynx was so full of growth that one could scarcely help catching something, and occasionally in growths at the anterior commissure, which are often difficult to seize with forceps.

It is in regard to the use of cutting instruments that cocaine anæsthesia has wrought a great change in our operative methods. Formerly, in using snares and guillotines, the reaction of the larynx, and the consequent tension of the cords, was calculated on to assist in getting hold of the yrowth. With complete aniesthesia this reaction falls out, and the snare or guillotine becomes much more difficult to use on a flaccid relaxed vocal cord. The result of this change has been emphasized in a recent article by one of the most experienced laryngologists now living, Prof. Stoerk of Vienna. He says : "To operate with the snare or guillotine has become no longer practicable. I now employ very powerful strong forceps, such as those of Gouguenheim, the blades of which have highly sharpened edges." It is interesting to observe how closely this agrees with the views expressed, nearly thirty years ago, by the late Sir Morell Hackenzie in his "Essay on Growths in the Larynx."

In France and America, and also in this country, a favourite instrument 
for many years has been a powerful cutting forceps, such as that of Mackenzie. I must confess that personally 1 have never been convinced of the advantages to be derived from the employment of such a powerful instrument in all forms of laryngeal growths, though I have had to use it in a few cases. In my experience this forceps prevents that accurate view of the field of operation which is indispensable to perfect safety, and I have therefore used for a number of years a sharp cutting forceps, fitting into Schroetter's handle, or the double curette of Krause. ${ }^{\mathrm{I}}$ I confess that I have been afraid of doing harm to normal structures with such large and powerful instruments as those of Mackenzie or Fauvel, a thing which has never happened to me in using those which I have described. That such an accident may happen, even to the most experienced, is evident from the fact that Mackenzic himself had in three cases out of a hundred to perform tracheotomy after the intralaryngeal removal of growths. I cannot imagine such an accident happening where an operation is carried out by fine cutting forceps, under full control of the eye. In this opinion I am confirmed by what Prof. Schroetter wrote to me some years agro. He then said that though he had opcrated on several hundred cases of laryngeal growths of all sizes, and in many where urgent dyspnoa was present, he had never required to perform a subsequent tracheotomy.

A form of cutting forceps which has been highly spoken of is that of our colleague, Dr. Dundas Grant. I have no cloubt it is an efficient instrument, though I have no personal experience of its use. I only object to its name of "Safety Cutting Forceps." Here as elsewhere safety must lie in the trained hand and eye of the operator rather than in the instrument. I am afraid the name may mislead the inexperienced. I would remind all such that Dr. Grant has himself recoreled at least one case in which he injured healthy parts with the "Safety Forceps," and I have myself seen a case in which a similar accident happened to another operator in using the same instrument.

I remember how the late Sir Morell Mackenzie, aware of the possibilities of harm which lay in his powerful forceps, used to insist that this instrument should never be introduced into the larynx more than once at the same sitting. As a contrast to this I should like to read you a case from Prof. Shroetter's lectures, which may not be known to some of the members present. It was one of a large papilloma attached along the edge of the right vocal cord and filling the cavity of the larynx. After a week's training of the patient Schroetter proceeded to operate. I give you a free translation of his words, which, to my mind, read more like the description of a siege than of a surgical operation. He says: "Next day, at 5.30 in the evening, I set myself to carry out this plan [ which was to separate the growth at its attachment with a knife]; but as it turned out that the patient was too sensitive to permit of operation with the knife being carried out, I was forced to remove each lobule of the growth with the pincette."

Naturally, such an operation required much time, and especially in this case, as the blceding obscured the mirror and the field of operation,

1 As the vast majority of simple laryngeal growths are small in size, the cases in which these fine forceps are not applicable are very few. 
so that often intervals of ten minutes must clapse, during which the patient sipped iced water. In this way we can understand that by halfpast eight about two-thirds of the growth had been removed. "I then gave the patient the option of putting off the remainder of the operation till next day, but told him I would rather finish it at the time. He at once agreed to go on, and after half an hour's rest we continued under the same difficulties to operate until half-past eleven, when I was convinced that the growth was completely cleared away. I then proceeded to cauterize with nitrate of silver. As this was followed by bleeding, some more time went past before I was able to convince myself that there was still a small portion anteriorly to be destroyed, and by the time this had been accomplished it was already half-past twelve o'clock." "It is years since this operation," say's Schroetter, "and I have often seen the patient since, but no recurrence has taken place." In this remarkable case I do not know whether to admire most the pluck and endurance of the patient or the skill and determination of the surgeon. It at least illustrates my point that a delicate instrument used skilfully may be introduced into the larynx an indefinite number of times without any bad result.

Cocaine anæsthesia has also largely done away with the argument in farour of the approach to a right angle which Mackenzic adopted in the construction of his forceps, in order to avoid touching the epiglottis. The catheter curve is now really an advantage, for by pressing on and raising the cpiglottis it cnables us to gret a much better view of the anterior part of the larynx. The catheter curved instrument is also more easily introduced and takes up less room in the pharynx.

The use of knives for the removal of laryngeal growths has found but little favour in this country, but in Germany many operators have employed them with success, and much controversy has gathered round the question whether they should be open or guarded. The dangers of the unguarded knife are very obvious, and Schroetter has published some cases illustrating the harm that may result from their use even in skilful hands. The advantage which Gottstein claimed for them, that they permitted the eye to follow the operation throughout, is no doubt true; but it seems to me that fine cutting forceps meet the same indications, and are in most hands much safer.

A third way of removing laryngeal growths is by curettage or scraping. This was the principle of the rough and imperfect sponge method of Voltolini. It is still mentioned in all text-books, and I suppose will continue to be for years to come. It never was a method of much practical value, and is now entirely superseded by more effective instruments. The use of Heryng's curettes for cases of diffuse multiple papillomata has been especially advocated by Massei, who speaks very highly of his success with these instruments. I have a few times used a curette with great effect in clearing out small warts at the base of the uvula and in the anterior commissure.

The destruction of laryngeal growths by caustics is not now advocated by anyone. For application to the base of a growth with a view to preventing recurrence both nitrate of silver and chromic acid are still 
sometimes employed. The former is too superficial in action to be of any real value, and chromic acid, which I used to employ, has now been replaced in my practice by the very delicate cutting forceps of Prof. Schmidt, of Frankfort, which enables one to remove the smallest scraps of growth, and so avoid the necessity for caustic applications. Of course this does not apply to laryngeal papillomata, for which we have as yet found no method to prevent recurrence. I think that brushing with pure lactic acid is probably the most effective application we know of at present.

The galvano-cautery has had its advocates, but can never be a safe instrument to use on a vocal cord. That it might be suitable for certain vascular tumours occurs to one, in view of the cases of severe, or even fatal, hæmorrhage recorded by Ferreri, Heinze, and Grünwald. But unfortunately we do not know beforehand the cases which are going to bleed, and fortunately this accident is an exceedingly rare one in the records of endolaryngeal operations for simple growths. For the destruction of so-called singers' nodes the galvano-cautery has also been recommended, but the fine forceps of Schmidt, already referred to, is a most effective and much safer instrument for this purpose.

Two methods of dealing with laryngeal growths which have been introduced in recent years, and of which I have no personal experience, are that of Scanes Spicer for operating under combined chloroform and cocaine anæsthesia, and the direct method of Kirschstein. Both methods have proved, I believe, of real value in those extremely difficult cases of multiple papillomata in young children.

\section{SOCIETIES' MEETINGS.}

\section{LARYNGOLOGICAL SOCIETY OF LONDON.}

Ordinary Meeting, June 9th, I897.

Hexry T. Butlin, Esq., F.R.C.S., in the Chair.

\section{Post-Mortem Specimens from a Case of Laryngectomy for Malignant} Disease of the Cricoid. Shown by Mr. G. SPENCER.

I complete the account of this case, which has previously been before the Society, because of the exceptional site of the disease, and also because the opinion is widely held that laryngectomy is seldom indicated. A single woman, aged forty-two, had worked for many years amongst steam and sometimes irritating vapours. Early in 1896 she suffered from her throat, and attended as an out-patient; but, growing worse, was admitted into the Westminster Hospital under Dr. Hall in August, 1896 .

She was suffering from subglottic obstruction, due to thickening all round within the cricoid ring, which was covered by normal mucous 